University of Wollongong

Research Online

Faculty of Engineering and Information

Faculty of Engineering and Information

Sciences - Papers: Part B

Sciences

2019

Microstructure and mechanical properties of large-volume gradientstructure aluminium sheets fabricated by cyclic skin-pass rolling

Hai Liang Yu

Central South University, hailiang@uow.edu.au

Cheng Lu

University of Wollongong, chenglu@uow.edu.au

Anh Kiet Tieu

University of Wollongong, ktieu@uow.edu.au

Hui Jun Li

University of Wollongong, huijun@uow.edu.au

Ajit R. Godbole

University of Wollongong, agodbole@uow.edu.au

See next page for additional authors

Follow this and additional works at: https://ro.uow.edu.au/eispapers1

Part of the Engineering Commons, and the Science and Technology Studies Commons

Research Online is the open access institutional repository for the University of Wollongong. For further information contact the UOW Library: research-pubs@uow.edu.au 


\title{
Microstructure and mechanical properties of large-volume gradient-structure aluminium sheets fabricated by cyclic skin-pass rolling
}

\author{
Abstract \\ Materials of a gradient structure have been shown to possess both high strength and high ductility. To \\ date, materials of a gradient structure can only be produced in small quantities. In this paper, we report a \\ novel 'cyclic skin-pass rolling' (CSPR) technique capable of producing sheets of gradient structure in large \\ quantities. Both experimental and analytical/numerical investigations are reported. In the experiments on \\ aluminium sheets, the outer layer was subjected to 40 passes of CSPR with a reduction ratio of $1 \%$ per \\ pass. After CSPR, the sample surface shows an ultrafine-grained microstructure with a mean grain size of \\ $206 \mathrm{~nm}$, while the annealed microstructure is retained in the core of the sample. Compared with cold- \\ rolled aluminium sheets fabricated with the same total reduction ratio, CSPR-processed aluminium \\ sheets have the same yield stress but improved uniform elongation (2.4 times). The scanning electron \\ microscopy was used to study the fracture surface, and The transmission electron microscopy to \\ examine the microstructure near the fracture end, in order to analyse the improvement in ductility. In \\ addition, the finite element method was used to simulate the roll-sample contact pressure and strain \\ distribution as well as residual stress on the sheet surface during CSPR, and to better understand the \\ mechanism leading to improvement of ductility of the sheets by the CSPR technique.

\section{Disciplines} \\ Engineering | Science and Technology Studies

\section{Publication Details} \\ Yu, H., Lu, C., Tieu, K., Li, H., Godbole, A., Liu, X. \& Kong, C. (2019). Microstructure and mechanical \\ properties of large-volume gradient-structure aluminium sheets fabricated by cyclic skin-pass rolling. \\ Philosophical Magazine, 99 (18), 2265-2284.

\section{Authors} \\ Hai Liang Yu, Cheng Lu, Anh Kiet Tieu, Hui Jun Li, Ajit R. Godbole, Xiong Liu, and Charlie Kong
}




\section{Microstructure and mechanical properties of large-volume gradient-structure aluminium sheets fabricated by cyclic skin-pass rolling}

Hailiang $\mathrm{Yu}^{\mathrm{a}, \mathrm{b}^{*}}$, Cheng $\mathrm{Lu}^{\mathrm{c}}$, Kiet Tieu${ }^{\mathrm{c}}$, Huijun $\mathrm{Li}^{\mathrm{c}}$, Ajit Godbolec, Xiong Liu${ }^{\mathrm{c}}$, Charlie Kong $^{\text {d }}$

a State Key Laboratory of High Performance Complex Manufacturing, Central South University, Changsha 410083, China

b School of Mechanical and Electrical Engineering, Central South University, Changsha 410083, China

c School of Mechanical, Materials, Mechatronics and Biomedical Engineering, University of Wollongong, NSW 2500, Australia

d Electron Microscope Unit, University of New South Wales, Sydney, NSW 2052, Australia

Abstract: Materials of a gradient structure have been shown to possess both high strength and high ductility. To date, materials of a gradient structure can only be produced in small quantities. In this paper, we report a novel 'cyclic skin-pass rolling' (CSPR) technique capable of producing sheets of gradient structure in large quantities.

Both experimental and analytical/numerical investigations are reported. In the experiments on aluminium sheets, the outer layer was subjected to forty passes of CSPR with a reduction ratio $1 \%$ per pass. After CSPR, the sample surface shows an ultrafine-grained microstructure with a mean grain size of $206 \mathrm{~nm}$, while the annealed microstructure is retained in the core of the sample. Compared with cold-rolled aluminium sheets fabricated with the same total reduction ratio, CSPR-processed

\footnotetext{
* Corresponding Author: YU H.L., Email: yuhailiang1980@tom.com or yuhailiang@csu.edu.cn.
} 
aluminium sheets have the same yield stress but improved uniform elongation (2.4 times). Scanning electron microscopy was used to study the fracture surface, and transmission electron microscopy to examine the microstructure near the fracture end, in order to analyze the improvement in ductility. In addition, the finite element method was used to simulate the roll-sample contact pressure and strain distribution as well as residual stress on the sheet surface during CSPR, and to better understand the mechanism leading to improvement of ductility of the sheets by the CSPR technique.

Keywords: gradient structure; aluminium sheet; ductility; finite element simulation; cyclic skin-pass rolling

\section{Introduction}

Nanograined/ultrafine-grained (NG/UFG) metals have higher strength compared to coarse-grained metals. This feature of NG/UFG metals has attracted much attention in recent years. Valiev [1] pointed out that NG/UFG metals fall in the category of 'advanced' materials. Estrin and Vinogradov [2] reviewed the development of NG/UFG materials in the past 25 years. To manufacture NG/UFG metals, a number of severe plastic deformation methods have been developed. Saito et al. [3] developed an accumulative roll bonding (ARB) technique to fabricate UFG metal sheets. Lee et al. [4] used ARB on a six-layer stack to produce high strength UFG aluminium sheets. Yu et al. [5] used a four-layer ARB technique to manufacture UFG aluminium sheets at room temperature. These sheets were shown to have good bonding quality. High 
pressure torsion is also an important severe plastic deformation method [6]. Joo et al. [7] studied the work-hardening-induced tensile ductility of high pressure torsion processed metallic glasses in bulk quantities. The equal channel angular press technique has also been widely used to fabricate NG/UFG materials [8]. Jafarlou et al. [9] studied the mechanical properties of AA6063 samples subjected to equal channel angular press. Asymmetric cryorolling is a technique which can be used to manufacture UFG metal sheets. Yu et al. [10] studied the grain refinement mechanism and mechanical properties of UFG aluminium alloy sheets fabricated using asymmetric cryorolling. In general, ductility and strength are contradictory properties in NG/UFG materials [11]. However, a number of potential applications demand the co-existence of ductility and strength in the material used. To enable greater applicability of NG/UFG bulk materials, it becomes necessary to attempt to improve their ductility, while also retaining their strength. Some heterogeneous microstructures with nanoscale to microscale grains have high strength and ductility [12, 13]. To facilitate this, a number of techniques such as formation of a gradient structure and formation of a bimodal structure have been discovered and developed as reviewed by Yu et al. [14].

Gradient-structure microstructures, in which the grain size decreases from micron level in the core to nanoscale at the surface, are found to result in higher ductility and strength as well as the fatigue life validated by experiments and theoretical analysis [15-21]. Thevamaran et al. [22] reported that extreme gradient nanograined structures in silver microcubes resulted in high strength and high toughness. Fang et al. [23] 
discovered the deformation mechanism of nanogradient $\mathrm{Cu}$ bars. Wu et al. [24] reported on the enhanced ductility in nanogradient interstitial-free steel bars. Yang et al. [25] used powder metallurgy to synthesize gradient-structure microstructures having enhanced toughness. However, to date, gradient-structure metals can only be fabricated in small quantities. A large-scale industrial application has not been reported due to a lack of reliable technologies capable of producing such materials in the form of sheets in large quantities. It would be desirable to produce such materials in sheet form in bulk quantities.

In the metal industries, more than $20 \%$ metal products are required in sheet form. Thus, it is important to develop a method to produce sheets of gradient-structure metal in large quantities. Skin-pass rolling (SPR) with a rolling reduction ratio of less than $1 \%$ is usually used as the final operational step for producing cold-rolled metal sheets [26]. Kijima [27] analyzed the effect of lubrication on the roughness of SPR-processed sheets. Giarola et al. [28] found that SPR affects the mechanical properties of sheets such as prevention of Lüder bands. Mehdi et al. [29] found that SPR affects the texture of steel sheets. However, to date, there have been no reports on the manufacture of gradient-structure metal sheets using SPR, or a variant thereof.

In this paper, we report for the first time a novel ‘cyclic skin-pass rolling' (CSPR) method to enable fabrication of gradient-structure aluminium sheets. The sheets were processed by forty passes of CSPR with a reduction ratio of $1 \%$ per pass. It was found that the ductility of these sheets improved greatly compared to sheets produced by traditional cold rolling (CR) while maintaining the strength. We also report a finite 
element simulation of the CSPR process, and propose a mechanism that leads to improvement in the ductility of the sheets manufactured by CSPR.

\section{Experimental Investigation}

Rolling experiments were carried out by using a 4-high multifunction rolling mill with $50 \mathrm{~mm}$ diameter work rolls made of the material Cr12 steel. The work rolls were newly polished before the experiment, resulting in a uniform deformation in the processed sheet along the rolling direction. The rolling was carried out under dry friction conditions at a speed of $40 \mathrm{~mm} / \mathrm{s}$. The commercial aluminium alloy 1060 (AA1060) was used as the test material. The nominal chemical composition (\% mass) of the alloy is Al-99.6, Si-0.25, Zn-0.05, Cu-0.05, Mg-0.03 and Mn-0.03. The roughness of AA1060 sheets is about $0.37 \mu \mathrm{m}$ [30]. The AA1060 sheets were $300 \mathrm{~mm}$ long and $60 \mathrm{~mm}$ wide. The thickness of the sheets before rolling was $1.5 \mathrm{~mm}$, which was reduced to $1.1 \mathrm{~mm}$ by CSPR and also by traditional CR (single pass) separately. Thus, it was ensured that the aluminium sheets have the same total reduction ratio after both CSPR and CR. In this study, the main difference between CSPR and CR is the rolling reduction ratio per pass. Figure 1 shows a schematic diagram of the CSPR process. Before the rolling experiments, finite element simulation of the process was carried out to determine the effect of rolling reduction ratio on the strain distribution in sheets. The simulation results were used to determine an optimum reduction ratio per pass. During CSPR, the sheets were processed forty passes with the rolling reduction ratio per pass is equal to or less than $1 \%$, and the error of rolling reduction ratio per pass is less than $5 \%$. 
Figure 1. Illustration of CSPR processing: rolling reduction ratio $\leqslant 1 \%$ per pass. The sheets were subjected to forty passes.

After rolling, the sheets were machined into tensile test samples with $25 \mathrm{~mm}$ gauge length and $6 \mathrm{~mm}$ gauge width in accordance with the ASTM D412 standard, as shown in Figure 2a. Tensile tests on an INSTRON machine were carried out to measure the engineering stress vs. strain curves, using a strain rate of $1.0 \times 10^{-3} \mathrm{~s}^{-1}$. The tensile tests were repeated three times. The scanning electron microscopy (SEM) technique was used to investigate the morphology of the fractured surface of the tensile tested samples.

Figure 2. Tensile test sample, (a) geometrical size, (b) illustration of sample subjected to CSPR, (c) Meshing and boundaries in FE model.

After CSPR and CR, the details of microstructure at the surface and in the core of the aluminium sheets were examined using a transmission electron microscope (TEM). After the tensile test, the details of microstructure near fracture tip were also inspected by TEM. The focused ion beam technique was used to manufacture TEM foil specimens from the rolled and tensile test samples, in which the TEM foil specimens were chosen from the top surface and the middle of the samples.

In order to analyze the experimental results, finite element (FE) method was used to simulate the rolling processing and the tensile tests. In the FE models, the geometrical 
parameters are the same with the experimental conditions. A two-dimensional FE model was developed on the LS-DYNA platform to study the strain distribution and residual stress in the sheet during rolling, using the model inputs as in the experiments. The Plastic-Kinematic material model was used for the aluminium sheet, for which the Young's modulus was set as $80 \mathrm{GPa}$, the yield stress $60 \mathrm{MPa}$ and the Poisson ratio 0.3. The roll was assumed to be perfectly rigid because the elastic deformation of rolls during aluminium rolling can be neglected. The Coulomb friction model was employed and the friction coefficient between the roll and sheet was set as 0.25. Figure 3 shows an image of the computational mesh near the rolling deformation zone of SPR processing. The mesh near the sheet surface was much finer compared to that in the core of the sheet, making a total of 31951 nodes and 28200 elements in the model. In addition, three-dimensional FE simulations were also carried out to study the strain distribution in the samples during the tensile test, in which the Gurson damage model was used. The Gurson damage model is described in Eq. (1).

$$
\Phi=\frac{\sigma_{e q}^{2}}{\sigma_{0}^{2}}+2 q_{1} f^{*} \cosh \left(-q_{2} \frac{3 p}{2 \sigma_{0}}\right)-\left(1+q_{1}^{2} f^{*^{2}}\right)
$$

where $p$ the hydrostatic pressure, $\sigma_{e q}$ the effective Von Mises stress, $\sigma_{0}$ the yield stress of the matrix (function of the plastic deformation), $q_{1}, q_{2}$ are material parameters and $f^{*}$ is the effective porosity. In this study, $q_{1}, q_{2}$ and $f^{*}$ are $1.5,1.0$ and 0.06 respectively [31]. The Young's Modulus was set as $80 \mathrm{GPa}$, and the Poison's ratio 0.3. For CR-processed sheets, according to the experimental results, the yield stress was set as $133 \mathrm{MPa}$. For CSPR-processed sheets, the yield stress of the UFG layer was set as $233 \mathrm{MPa}$, and $55 \mathrm{MPa}$ for the coarse-grained layer. These values are considered the 
grain size effect and calculated by the Hall-Petch equation according to the mean grain size as follows [20, 21]. For the three-dimensional tensile test simulation, there are 78554 nodes and 70200 elements. The FE model of tensile test was shown in Fig. 2b and 2c. One side of sample was constrained. And the load was added in another side of sample according to the experimental parameters.

Figure 3. Finite element meshing of sheet and roll near rolling deformation zone.

\section{Results}

\subsection{Mechanical properties}

Figure 4 shows the engineering strain vs. engineering stress curves of the CSPR-processed and CR-processed and annealed sheets during the tensile test. Table 1 lists the yield stress and uniform strain of the sheets subjected to CSPR and CR respectively. We can observe that the yield stress of CSPR-processed sheets (129 MPa) has similar value with that of sheets subjected to CR (133 MPa), which enhance greatly compared to the annealed sheets (55 MPa). However, in Table 1, the uniform strain of CR-processed aluminium sheets is 0.05 , which increases to 0.12 for the CSPR-processed aluminium sheets, by a factor of 2.4. It is obvious that the CSPR-processed sheets have more desirable qualities such as enhanced ductility without sacrificing the yield strength, compared with sheets produced by CR. 
Figure 4. Engineering stress-strain curves of CSPR-processed, CR-processed and annealed sheets.

Table 1. Yield stress and uniform strain for the CSPR-processed and CR-processed samples.

\subsection{Microstructure of sheets after rolling}

Figure 5 shows TEM images of the samples after CR and CSPR processing. In Figure 5a1 and Figure 5a2, the microstructures at the sample surface are seen to be similar to those in the sample core after CR. The grain sizes for the CR-processed samples are in the range $0.6 \mu \mathrm{m}$ to $1.8 \mu \mathrm{m}$. During CR, the plastic strain in sheets is uniform, which results in the same microstructure in the sheets. Figure 6 shows the grain size distribution by the statistics based on the size of 100 grains. Figure 6a and Figure 6b show the grain size distribution near the surface and in the core region of the aluminium sheets processed by CR. The mean grain size near the surface (998 nm) is only slightly smaller than that in the core $(1004 \mathrm{~nm})$. However, with the CSPR technique, a large difference between the grain size at the sample surface and in the sample core is seen, as shown in Figure $5 b 1$ and Figure 5b2. Figure 6c shows the grain size distribution below the sample surface after subjected to CSPR, showing the majority of grains ranging from $160 \mathrm{~nm}$ to $320 \mathrm{~nm}$, with a mean grain size of $206 \mathrm{~nm}$. It is also seen that the annealed microstructure is retained in the core of sample. 
Figure 6d shows the grain size distribution in the center of sample subjected to CSPR, in which the majority of grains is between $1600 \mathrm{~nm}$ and $2400 \mathrm{~nm}$, with a mean grain size of $2001 \mathrm{~nm}$. During CSPR, the plastic strain only appears near the surface of aluminium sheet, which results in much finer grain size near the sheet surface. It is obvious that the CR-processed samples have a relatively uniform microstructure and that the CSPR-processed samples have a gradient-structure microstructure.

Figure 5. TEM images of rolled samples: (a1) surface and (a2) core of CR-processed samples respectively; (b1) surface and (b2) core of CSPR-processed samples

$$
\text { respectively. }
$$

Figure 6. Grain size distribution. (a) near surface of aluminium sheet by CR, (b) center of aluminium sheet by CR, (c) near surface of aluminium sheet by CSPR, and (d) center of aluminium sheet by CSPR.

\subsection{Fracture surface and geometrical shape of sheets after tensile tests}

Figure 7 shows SEM images of the fracture surfaces of the tensile-tested samples: Figure 7a1-7a3 for the samples processed by CR, and Figure 7b1-7b3 for those processed by CSPR. After necking, the thickness of necking zone is about $0.5 \mathrm{~mm}$, indicating that Figure 7a1 and Figure 7b1 show more than half of the fracture surface $(>0.3 \mathrm{~mm})$. Figure 7a1 shows a serrated fracture surface for the samples subjected to CR. The geometric shape of fracture surface is the same with the results reported by Benzerga et al.[32], in which the fracture occurs in the sample center firstly. In 
addition, the dimples near the sample core are smoother and shallower than those near the sample surface, as shown in Figure $7 \mathrm{a} 2$ and $7 \mathrm{a} 3$. Figure $7 \mathrm{~b} 1$ shows a fully deformed fracture surface under shear, with deeper dimples near the sample core than near the sample surface for the samples subjected to CSPR. A detailed view of the dimples is shown in Figure 7b2 and 7b3. Compared fracture surfaces in Figure 7a2 and Figure 7b2, they have similar dimple surfaces and dimple development regularity that the dimples are developed towards the sample surface, which means the fractures appear in the sample center firstly and then propagate to the sample surface. In Figure 7a3 and Figure 7b3, there are many differences for the shape of dimples. For the samples subjected to $\mathrm{CR}$, the dimples are small and shape, and the fracture surface are relative smooth. For the samples subjected to CSPR, the dimples are oval shape, and depth of most of the dimples is heavy. These observations suggest a mechanism for the observed improvement in the ductility of sheets produced by CSPR compared to those produced by CR. Figure 8 shows the geometric shapes of the fractured end of both CSPR-processed and CR-processed samples (also shown in Figure 4) for the cross section of the tensile direction and thickness direction. It is obvious that the CSPR-processed sample has greater deformation near the necking zone compared to that subjected to CR-processing, which implies a higher ductility of the CSPR-processed samples.

Figure 7. Fracture surface of samples. (a1)-(a3) for cold rolling, (a2) for sample surface and (a3) for sample core; (b1)-(b3) for skin-pass rolling, (b2) for sample surface and (b3) for sample core. 
Figure 8. Geometrical shape of fractured samples after tensile test.

\subsection{Microstructure near fracture end after tensile tests}

Figure 9a shows a TEM image of the microstructure near the fracture end of CR-processed samples from the cross section of the width direction and thickness direction (The TEM sample positions are shown in Figure 4). The fracture appears in the midst of a relatively uniform microstructure. Figure 9b shows a TEM image of the microstructure near the fracture end of the sample processed by CSPR. We can observe that the fracture first appears in the coarse-grained zone (core). In the gradient-structure micro-structure, the uniform nano-size grains in the sample surface can effectively inhibit crack initiation, as has also been reported by Zhao et al [33] and Huang et al [34]. Compared with the microstructure in the CR-processed aluminium sheets, the CSPR technique retains the original annealed microstructure in the core due to low plastic deformation. This may directly explain the great improvement in ductility of sheets fabricated by CSPR.

Figure 9. TEM images of fracture end of sheets by (a) CR and (b) CSPR respectively.

\section{Discussion}

\subsection{Deformation behavior of sheet during rolling}

During CR, the strain in the sheet is nearly uniform due to large reduction ratio. 
However, the deformation only appears in the surface layer of the sheet during SPR. Figure 10 shows the roll-sample contact pressure distribution in the strip when the reduction ratio is in the range of $0.5 \%$ to $2.0 \%$. When the rolling reduction is very small, the pressure is only concentrated near the sheet surface. In the figure, with increasing in rolling reduction ratio, the depth of the high-pressure region gradually increases.

Figure 10. Pressure distribution in sheet during SPR with rolling reduction ratio (a)

$$
0.5 \% \text {, (b) } 1.0 \% \text {, (c) } 1.5 \% \text { and (d) } 2.0 \% \text {. }
$$

During deformation, grain refinement in the aluminium alloy is determined by the plastic strain. Figure 11a shows the plastic strain distribution in the sheet during SPR with a rolling reduction ratio of $0.5 \%$. The plastic strain mainly appears near the sheet surface, and there is no deformation in the sheet core. Figure 11b shows the strain distribution across the sheet cross section for four reduction ratios. A $0.12 \mathrm{~mm}$ thick region near the sheet surface shows plastic deformation when the rolling reduction ratio is $0.5 \%$. As the rolling reduction ratio increases to $1 \%$, the thickness of plastic strain region grows to $0.17 \mathrm{~mm}$. The thickness of plastic strain region further increases with higher rolling reduction ratio. For the rolling reduction ratio $1.5 \%$, the thickness of plastic strain region grows to $0.25 \mathrm{~mm}$. Plastic strain appears throughout the sheet cross section when the rolling reduction ratio increases to $2 \%$. Figure 11c shows the ratio of plastic strain zone thickness to sheet thickness for different rolling reduction ratios. If the rolling reduction ratio is less than $1 \%$, the ratio of the thickness 
of plastic strain region to the thickness of sheet is around $20 \%$. For a rolling reduction ratio of $2 \%$, the ratio of the thickness of plastic strain region to the thickness of sheet increases to $100 \%$. This indicates that the rolling reduction ratio per pass during CSPR is a crucial parameter that needs to be controlled in fabricating gradient--structure sheets. In this study, the rolling reduction ratio per pass during CSPR is less than $1 \%$, thus the grain size near the sample surface is refined greatly compared to that in the center of sheet, as represented in Figure $5 \mathrm{~b} 1$ and 5b2. In Figure 5b2, the annealed microstructure is kept in the sheet center which matches the simulation results quite well that there is no plastic strain in the center region.

Figure 11. (a) strain distribution in sheet during skin pass rolling with rolling reduction ratio $0.5 \%$; (b) strain distribution corresponding to different reduction ratios.

\subsection{Enhanced mechanical properties of CSPR-processed sheets}

In Figure 4, we observe that materials of a gradient structure show a similar yield stress but improved ductility compared to CR-processed samples. In this study, the total reduction ratio during CR equals to that during CSPR. The yield stress of the sheets may be related to the total strain. In the following paragraphs, we propose two mechanisms that may explain the improvement in the ductility of the sheets.

The main feature of materials of a gradient structure is that the grain size distribution across sheets is non-uniform. There have been three kinds of structures with non-uniform grain size distribution reported to date. These have been shown to 
have both high strength and high toughness. (1) The bimodal structure: The bimodal structure was first discovered in cryorolled and annealed copper sheets by Wang et al. [35]. Witkin et al. [36] found that the bimodal structure can achieve high strength and improved ductility of an $\mathrm{Al}-\mathrm{Mg}$ alloy. Yu et al. [37] found that aluminium sheets subjected to ARB and subsequent asymmetric rolling develop a bimodal structure with high strength and high ductility. (2) The trimodal structure: Jiang et al. [38] first developed a trimodal composite material that combines the physical and mechanical properties of different phases. Zhang et al. [39] fabricated a trimodal structure composite using cryomilling of powders and high pressure torsion. They found that both strength and ductility of the composite improves during high pressure torsion. (3) The gradient structure: In this case, the outside (surface) is made up of nano-size grains, and inside is composed of coarse grains. Two mechanisms have been proposed to explain the improvement in strength and ductility: (i) grain coarsening and grain softening (nano grains) + grain refinement and grain hardening (coarse grains) [15], and (ii) strain hardening induced by a macroscopic strain gradient [16]. However, there are no reports that the outside is made of coarse-grains and the inside is made of nano-grains which also show high strength and high ductility. We propose that the deformation features during tensile test may contribute to the improvement of ductility of gradient--structure samples.

Figure 12 shows the FE simulation results of the maximum plastic strain vs elongation in CR-processed and CSPR-processed samples subjected to tensile tests, in which the maximum plastic strain occurs in the center region of samples due to the 
symmetrical shape and thick thickness during tensile tests. Benzerga et al. [32] reported the tensile test experimental results in which the cracks initiate and propagate from the sample center region. At beginning, the maximum strain in CR-processed sample is similar to that in CSPR-processed sample. However, with increasing the elongation, the maximum strain in CR-processed sample becomes larger than that of CSPR-processed sample for the same elongation. In addition, the necking begins in CR-processed sample when the elongation reaches $1.25 \mathrm{~mm}$, which is much faster than that in CSPR-processed sample. From the strain distribution near necking regions, the strain in CR-processed sample is less uniform than that in CSPR-processed sample, which validates the difference of the geometric shape near necking region in Figure 7. Lyu et al [21] developed a physically-based multi-scale modeling framework to investigate materials with gradient structures which validated the achievable combination of high strength and high ductility. They pointed out materials with banded nano-structure can have higher ductility by delaying strain localization [21]. Lu et al [40] pointed out that the grain growth helps to smooth the inhomogeneous distribution of stress and strain which suppresses strain localization and plays an important role in enhanced ductility of gradient materials. The grain growth has been observed in rolled UFG materials [41]. Yuan et al. [42] also reported the ductility by shear band delocalization in the nano-layer of gradient structure. In Figure 12, it is obvious that the gradient structure can delay the strain localization, which contributes to the improved ductility. 
Figure 12. Maximum plastic strain in CR-processed and CSPR-processed samples vs elongation during tensile test.

In addition, the equivalent plastic strain in sample center is larger than that in sample surface during tensile test. Figure 13 shows the difference of the plastic strain between sample center and sample surface. The difference of the plastic strain between sample center and sample surface for CSPR-processed sample is larger than that for CR-processed sample before necking. In addition, the difference of the plastic strain increases greatly after necking for both CSPR-processed and CR-processed samples. If a crack appears in the core of sample, it will propagate rapidly. CR-processed sheets have a relatively uniform microstructure with refined grains. Generally, the finer the grain size, the lower is the ductility of the sheet for most of metals. In addition, the sheets may have some minor defects close to the inclusions due to plastic deformation in rolling processing [43], which will also reduce the ductility of the sheets. In Figure $6 \mathrm{~b}$, the cracks are seen to originate from the coarse-grain layer for the CSPR-processed sheets.

Figure 13. Plastic strain difference between sample center and surface in CR-processed and CSPR-processed samples vs elongation during tensile test.

There are some studies in which it was seen that the residual stress distribution through sheet thickness also has effect on the mechanical properties of materials [17-19]. Dai and Shaw [19] reported that the residual compressive stresses near sample surface contributed to the improved fatigue resistance of nanograined samples. 
Zhao et al. [33] found that the compression stress close to sheet surface contributes to the improved fatigue properties of a TC11 alloy after ultrasonic impacting and rolling treatment. Huang et al. [34] found that the compressive stress below the sample surface by pre-rolling with a small reduction results in higher damage tolerance of an Al-Cu-Mg alloy. In the current study, we also propose that the compressive stress near the sheet surface contributes to the improved ductility due to the suppression of crack opening near sample surface. Hattori et al. [44] pointed out that FE analysis is a useful tool to study the distribution of residual stress in rolled sheets. Figure $\mathbf{1 4}$ shows the residual stress in the rolling direction after rolling for different rolling reduction ratios. For aluminium sheets, when the reduction ratio is $0.5 \%$ and $1 \%$, the residual stress in a large region near sheet surface is compressive, as shown in Figure 14a and Figure 14b respectively. This kind of stress distribution is the same with the report on a C-2000 alloy after surface severe plastic deformation by Dai and Shaw [19]. Hattori et al. [44] also found that the residual stress in the rolling direction is compressive at the surface and tensile at about quarter thickness from the surface when the rolling reduction is low with small rolls and low friction coefficient. However, when the reduction ratio increases to $2 \%$, the surface residual stress transforms into tensile stress, as shown in Figure 14c. Figure 14d shows that the residual stress below the sheet surface changes from compressive stress into tensile stress for higher rolling reduction ratios.

Figure 14. Residual stress in sheet after a rolling pass for rolling reduction ratio (a) 
$0.5 \%$, (b) $1.0 \%$, (c) $2.0 \%$. (d) residual stress cross the sheet thickness.

Figure 15 shows the evolution of stress distribution and the evolution of stress cross the sheet thickness during tensile processing when the residual stresses in sheets after rolling (Figure 14) have been considered, in which the same load is set in FE models. Figure 15a1-Figure 15d1 show the evolution of stress distribution during tensile processing when the reduction ratio is set as $0.5 \%$, and Figure 15a2-Figure $15 \mathrm{~d} 2$ for $2.0 \%$. It is obvious that the evolution of stress distribution for the sheets with different residual stresses has great difference during tensile processing. During tensile processing, when the reduction ratio is set as $0.5 \%$ or $1.0 \%$, the stress near the sheet center increases greatly, however, the stress near sheet surface increases slightly, as shown in Figure 15e and Figure 15f. When the reduction ratio is set as $1.5 \%$ or $2.0 \%$, although the stress near the sheet center increases with loading, however the value of stress near sheet center is much lower than that in the sheets with reduction ratio $0.5 \%$ and $1.0 \%$. In addition, the stress near sheet surface increases continuously, as shown in Figure 15g and Figure 15h. For the step 3, the yield regions in Figure 15e and Figure $15 \mathrm{f}$ are close to zero mm, but the yield regions in Figure 15g and Figure $15 \mathrm{~h}$ are near $0.1 \mathrm{~mm}$. In addition, with the reduction ratio increases, the yield region increases at the same time step. It is obvious that the sheets which appear plastic deformation earlier will have lower ductility. Yang et al. [45] reported that the "back stress" in gradient structure materials subjected to surface mechanical attrition treatment contributes to the improved strength and ductility. Yang et al. [46] also reported that the "back stress" contributes to the improved ductility of a 
medium-entropy alloy. Thus, the residual stress distribution in sheets with low reduction ratio may also contribute to the improvement in ductility of the gradient--structure aluminium sheets.

Figure 15. Evolution of stress during tensile processing considered the residual stress after rolling, (a1)-(d1) for reduction ratio $0.5 \%$ and (a2)-(d2) for reduction ratio $2.0 \%$. Stress value cross the sheet thickness during tensile processing considered the residual stress for rolling reduction ratio (e) $0.5 \%$, (f) $1.0 \%$, (g) $1.5 \%$ and (h) $2.0 \%$. Here, step 1, 2 and 3 are time step of $0.05 \mathrm{~s}$ in FE model.

\section{Conclusions}

(1) A novel 'cyclic skin-pass rolling' (CSPR) technique has been developed to fabricate gradient-structure metal sheets. Compared with the sheets manufactured by cold rolling, the CSPR-processed sheets show a comparable yield strength and 2.4 times the uniform strain. The gradient structure and compression stress near sheet surface contribute to the higher ductility of the sheets.

(2) The theory that the fracture originates in the sample core can be used to explain the improvement of ductility of sheets by skin-pass rolling technique compared to that by cold rolling. This was also observed in the TEM images of the microstructure near the fracture end of the tensile tested samples as well as in the SEM images of the fracture surface.

(3) The rolling reduction ratio per pass during CSPR determines the mechanical properties of sheets. If the rolling reduction ratio is $<1 \%$, the ratio of the thickness of plastic strain region to the sheet thickness is $<20 \%$. 
(4) FE simulation results show that the maximum plastic strain in CSPR-processed samples is lower than that in CR-processed samples with the same elongation during tensile test, in which the gradient structure can delay the strain localization. FE simulation results also show that the residual stress in sheets also have great effect on the plasticity deformation of sheets during tensile test. These two kinds of reasons can explain the higher ductility observed in CSPR-processed sheets.

\section{Acknowledgements}

This research was supported by National Natural Science Foundation of China (Grant number: 51674303), National Youth Thousand Plan Program of China, Huxiang High-Level Talent Gathering Project of HUNAN Province (Grant number: 2018RS3015), Innovation Driven Program of Central South University (Grant number: 2019CX006), the Research Fund of the Key Laboratory of High Performance Complex Manufacturing at Central South University, and the Australian Research Council Development Project (Grant number: DP170103092).

\section{References}

[1] R.Z. Valiev, Nanostructuring of metals by severe plastic deformation for advanced properties, Nature Mater. 3(2004), pp. 511-516.

[2] Y. Estrin, and A. Vinogradov, Extreme grain refinement by severe plastic deformation: A wealth of challenging science, Acta Mater. 61(2013), pp. 782-817.

[3] Y. Saito, H. Utsunomiya, N. Tsuji, and T. Sakai, Novel ultra-high straining process 
for bulk materials development of the accumulative roll-bonding (ARB) process, Acta Mater. 47(1999), pp. 579-583.

[4] S.H. Lee, H. Inagaki, H. Utsunomiya, Y. Saito, and T. Sakai, Ultra grain refinement of commercial purity aluminum by a multi-stack ARB process. Mater. Trans. 44 (2003), pp. 1376-1381.

[5] H.L. Yu, C. Lu, K. Tieu, and C. Kong, Fabrication of nanostructured aluminum sheets using four-layer accumulative roll bonding, Mater. Manuf. Process. 29 (2014), pp. 448-453.

[6] A.P. Zhilyaev, and T.G. Langdon, Using high-pressure torsion for metal processing: Fundamentals and applications, Prog. Mater. Sci. 53 (2008), pp. 893-979.

[7] S.H. Joo, D.H Pi,. A.D.H. Setyawan, H. Kato, M. Janecek, Y.C. Kim, S. Lee, and H.S. Kim, Work-hardening induced tensile ductility of bulk metallic glasses via high-pressure torsion, Sci. Rep. 5 (2015), p. 9660.

[8] R.Z. Valiev, T.G. Langdon, Principles of equal-channel angular pressing as a processing tool for grain refinement, Prog. Mater. Sci. 51 (2006), pp. 881-981.

[9] D.M. Jafarlou, E. Zalnezhad, A.S. Hamouda, G. Faraji, N.A.B. Mardi, and M.A. Hassan Mohamed, Evaluation of the mechanical properties of AA6063 processed by severe plastic deformation, Metall. Mater. Trans. A 46 (2015), pp. 2172-2184.

[10] H.L. Yu, C. Lu, K. Tieu, X.H. Liu, Y. Sun, Q.B. Yu, and C. Kong, Asymmetric cryorolling for fabrication of nanostructured aluminum sheets, Sci. Rep. 2 (2012), p. 772. 
[11] R.O. Ritchie, The conflicts between strength and toughness, Nature Mater. 10 (2011), pp. 817-822.

[12] H. Lyu, N. Taheri-Nassaj, and H. Zbib, A multiscale gradient-dependent plasticity model for size effects. Philos. Mag. 96 (2016), pp. 1883-1908.

[13] M. Hamid, H. Lyu, and H. Zbib, A dislocation-based stress-strain gradient plasticity model for strength and ductility in materials with gradient microstructures. Philos. Mag. 98 (2018), pp. 2896-2916.

[14] H.L. Yu, C. Lu, K. Tieu, H.J. Li, A. Godbole, and S.H. Zhang, Special rolling techniques for improvement of mechanical properties of ultrafine-grained metal sheets: A review, Adv. Eng. Mater. 18 (2016), pp. 754-769.

[15] K. Lu, Making strong nanomaterials ductile with gradients, Science 345 (2014), pp. $1455-1456$

[16] J. Li, S. Chen, X. Wu, A.K. Soh and J. Lu, The main factor influencing the tensile properties of surface nano-crystallized graded materials. Mater. Sci. Eng. A 527(2010), pp. 7040-7044.

[17] J. Villegas, L. Shaw, K. Dai, W. Yuan, J. Tian, P. Liaw, and D. Klarstrom, Enhanced fatigue resistance of a nickel-based Hastelloy induced by a surface nanocrystallization and hardening process. Philos. Mag. Lett. 85 (2005) 427-438.

[18] J.W. Tian, J. Villegas, W. Yuan, D. Fielden, L. Shaw, P.K. Liaw, and D.L. Klarstrom, A study of the effect of nanostructured surface layers on the fatigue behaviors of a C-2000 superalloy. Mater. Sci. Eng. A 468-470 (2007), pp. 
164-170.

[19] K. Dai, and L. Shaw, Analysis of fatigue resistance improvements via surface severe plastic deformation. Int. J. Fatigue 30 (2008), pp. 1398-1408.

[20] J. Li, S. Chen, X. Wu, A.K. Soh, A physical model revealing strong strain hardening in nano-grained metals induced by grain size gradient structure. Mater. Sci. Eng. A 620(2015), pp.16-21.

[21] H. Lyu, M. Hamid, A. Ruimi, and H. Zbib, Stress/strain gradient plasticity model for size effects in heterogeneous nano-microstructres. Int. J. Plasticity, 97 (2017) 46-63.

[22] R. Thevamaran, O. Lawal, S. Yazdi, S.J. Jeon, J.H. Lee, and E.L. Thomas, Dynamic creation and evolution of gradient nanostructure in single-crystal metallic microcubes, Science 354 (2016), pp. 312-316.

[23] T.H. Fang, W.L. Li, N.R. Tao, and K. Lu, Revealing extraordinary intrinsic tensile plasticity in gradient nano-grained copper, Science 331 (2011), pp. 1587-1590.

[24] X. Wu, P. Jiang, L. Chen, F. Yuan, and Y.T. Zhu, Extraordinary strain hardening by gradient structure, Proc. Natl. Acad. Sci. U. S. A. 111 (2014), pp. 7197-7201.

[25] H. Yang, E. J. Lavernia, and J. M. Schoenung, Novel fabrication of bulk Al with gradient grain size distributions via powder metallurgy, Philos. Mag. Lett. 95 (2015), pp. 177-186.

[26] S. Kalpakjian, Manufacturing processes for engineering materials, second ed. Addison-Wesley, Reading, Mass, (1991) p.356. 
[27] H. Kijima, Influence of lubrication on roughness crushing in skin-pass rolling of steel strip, J. Mater. Process. Technol. 216 (2015), pp. 1-9.

[28] A.M. Giarola, P.H.R. Pereira, P.A. Stemler, A.E.M. Pertence, H.B. Campos, M.T.P. Aguilar, and P.R. Cetlin, Strain heterogeneities in the rolling direction of steel sheets submitted to the skin pass: A finite element analysis, J. Mater. Process. Technol. 216 (2015), pp. 234-247.

[29] M. Mehdi, Y. He, E.J. Hilinski, and A. Edrisy, Effect of skin pass rolling reduction rate on the texture evolution of a non-oriented electrical steel after inclined cold rolling, J. Magn. Magn. Mater. 429 (2017), pp. 148-160.

[30] W.J. Sun, Research on surface roughness of cold-rolled plate and strip, Alum. Fabr. 3 (2008), pp. 42-44.

[31] A. L. Gurson, Continuum theory of ductile rupture by void nucleation and growth: part i---yield criteria and flow rules for porous ductile media. J. Eng. Mater. Technol. 99(1977), pp.2-15.

[32] A.A. Benzerga, J. Besson, A. Pineau. Anisotropic ductile fracture Part I: experiments. Acta Mater. 52 (2004) 4623-4638.

[33] X. Zhao, G. Xue, and Y. Liu, Gradient crystalline structure induced by ultrasonic impacting and rolling and its effect on fatigue behavior of TC11 titanium alloy, Res. Phys. 7 (2017), pp. 1845-1851.

[34] T. Huang, Q. Zhao, Z. Liu, and S. Bai, Enhanced damage tolerance through reconstructing residual stress and CuMg co-clusters by pre-rolling in an Al-Cu-Mg alloy, Mater. Sci. Eng. A 700 (2017), pp. 241-249. 
[35] Y. Wang, M. Chen, F. Zhou, and E. Ma, High tensile ductility in a nanostructured metal, Nature 419 (2002), pp. 912-915.

[36] D. Witkin, Z. Lee, R. Rodriguez, S. Nutt, and E. Lavenia, Al-Mg alloy engineered with bimodal grain size for high strength and increased ductility, Scr. Mater. 49 (2003), pp. 297-302.

[37] H.L. Yu, K. Tieu, S. Hadi, C. Lu, A. Godbole, and C. Kong, High strength and ductility of ultrathin laminate foils using accumulative roll bonding and asymmetric rolling, Metall. Mater. Trans. A 46 (2015), pp. 869-879.

[38] L. Jiang, K. Ma, H. Yang, M. Li, E.J. Lavernia, and J.M. Schoenung, The microstructural design of trimodal aluminum composites, JOM 66 (2014), pp. 898-908.

[39] Y. Zhang, S. Sabbaghianrad, H. Yang, T.D. Topping, T.G. Langdon, E.J. Lavernia, J.M. Schoenung, and Nutt, S.R. Two-step spd processing of a trimodal al-based nano-composite, Metall. Mater. Trans. A 46 (2015), pp. 5877-5886.

[40] X. Lu, X. Zhang, M. Shi, F. Roters, G. Kang, D. Raabe. Dislocation mechanism based size-dependent crystal plasticity modeling and simulation of gradient nano-grained copper. Int. J. Plasticity, 113 (2019), pp. 52-73.

[41] H.L. Yu, C. Lu, A.K. Tieu, H.J. Li, A. Godbole, C. Kong, X. Zhao. Simultaneous grain growth and grain refinement in bulk ultrafine-grained copper under tensile deformation at room temperature. Metall. Mater. Trans. A 47 (2016), pp. 3785-3789.

[42] F.P. Yuan, D.S. Yan, J.D. Sun, L.L. Zhou, Y.T. Zhu, X.L. Wu. Ductility by shear 
band delocalization in the nano-layer of gradient structure. Mater. Res. Lett. 7 (2019), pp.12-17.

[43] H.L. Yu, X.H. Liu, H.Y. Bi, and L.Q. Chen, Deformation behavior of inclusions in stainless steel strips during multi-pass cold rolling, J. Mater. Process. Technol. 209 (2009), pp. 455-461.

[44] N. Hattori, R. Matsumoto, and H. Utsunomiya, Residual stress distribution through thickness in cold-rolled aluminum sheet, Key Eng. Mater. 622-623 (2014), pp. 1000-1007.

[45] M. Yang, Y. Pan, F. Yuan, Y. Zhu, X. Wu. Back stress strengthening and strain hardening in gradient structure. Mater. Res. Lett. 4 (2016), pp. 145-151.

[46] M. Yang, D. Yan, F. Yuan, P. Jiang, E. Ma, X. Wu. Dynamically reinforced heterogeneous grain structure prolongs ductility in a medium-entropy alloy with gigapascal yield strength. Proc. Natl. Acad. Sci. U. S. A. 115 (2018) 7224-7229. 


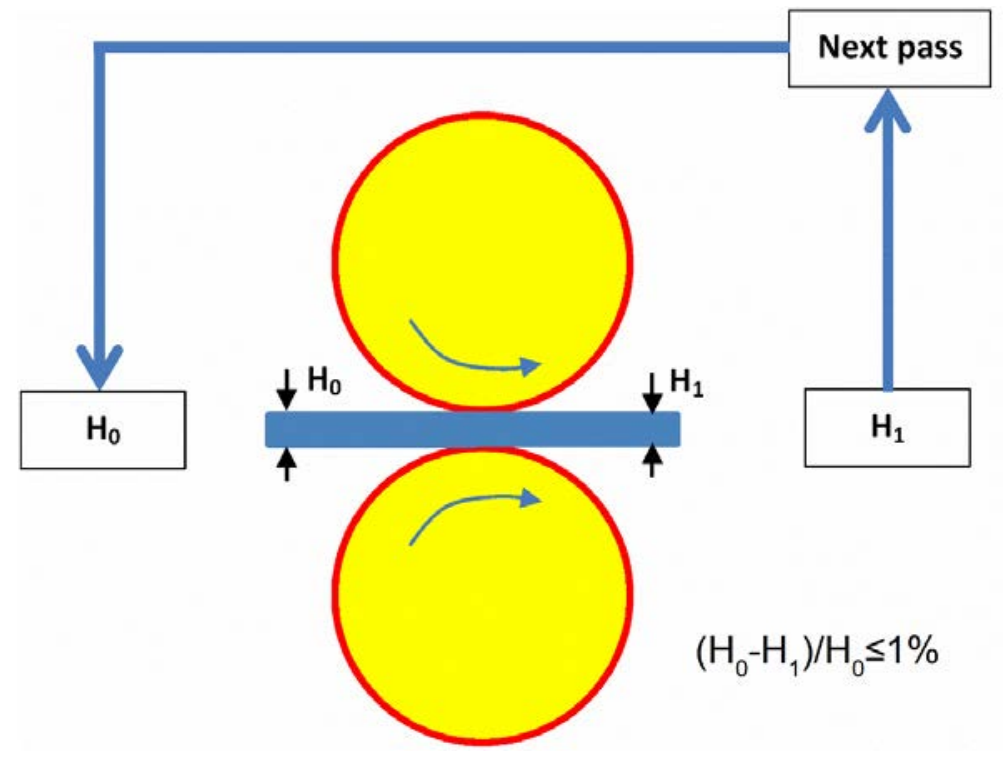

Figure 1. Illustration of CSPR processing: rolling reduction ratio $\leqslant 1 \%$ per pass. The sheets were subjected to forty passes. 


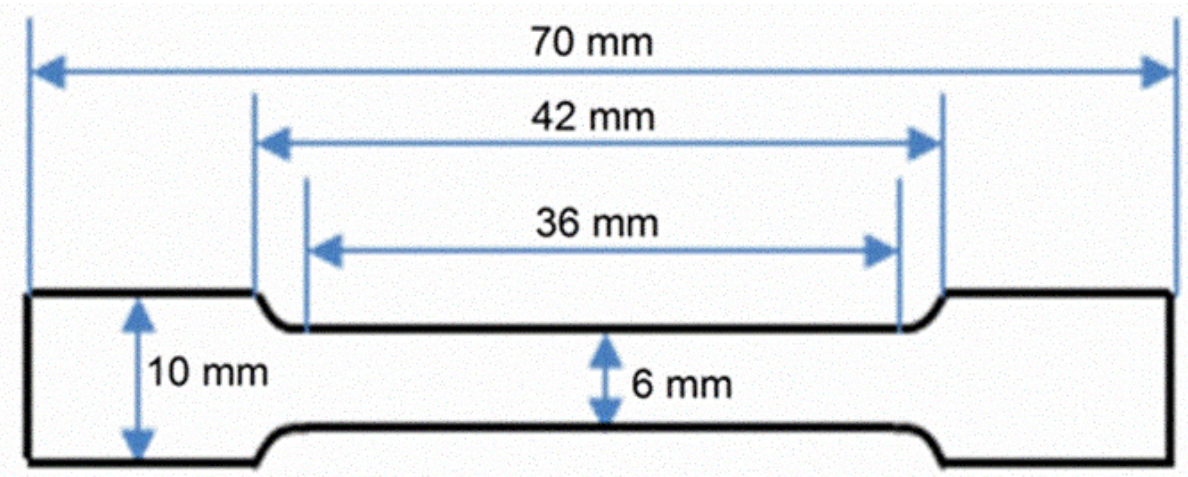

Figure 2. Schematic of tensile test sample. 

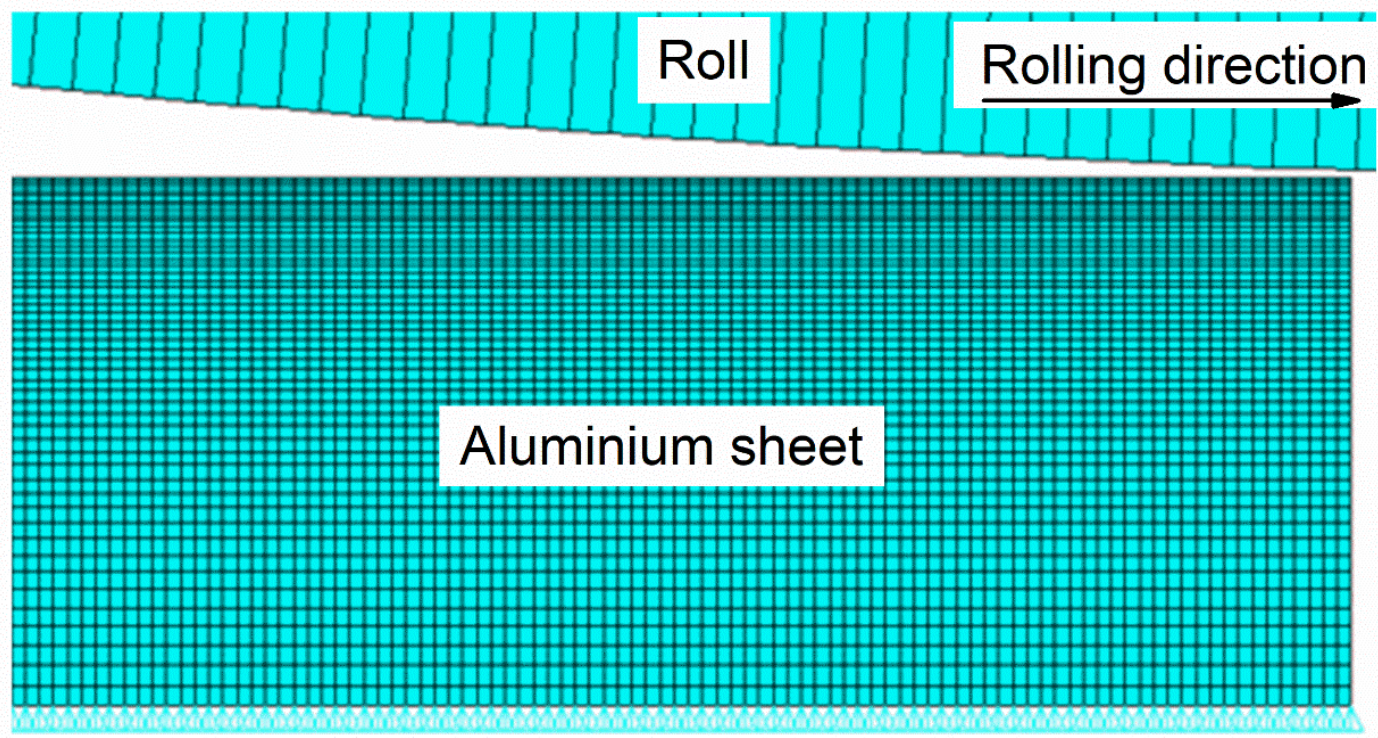

Figure 3. Finite element meshing of sheet and roll near rolling deformation zone. 


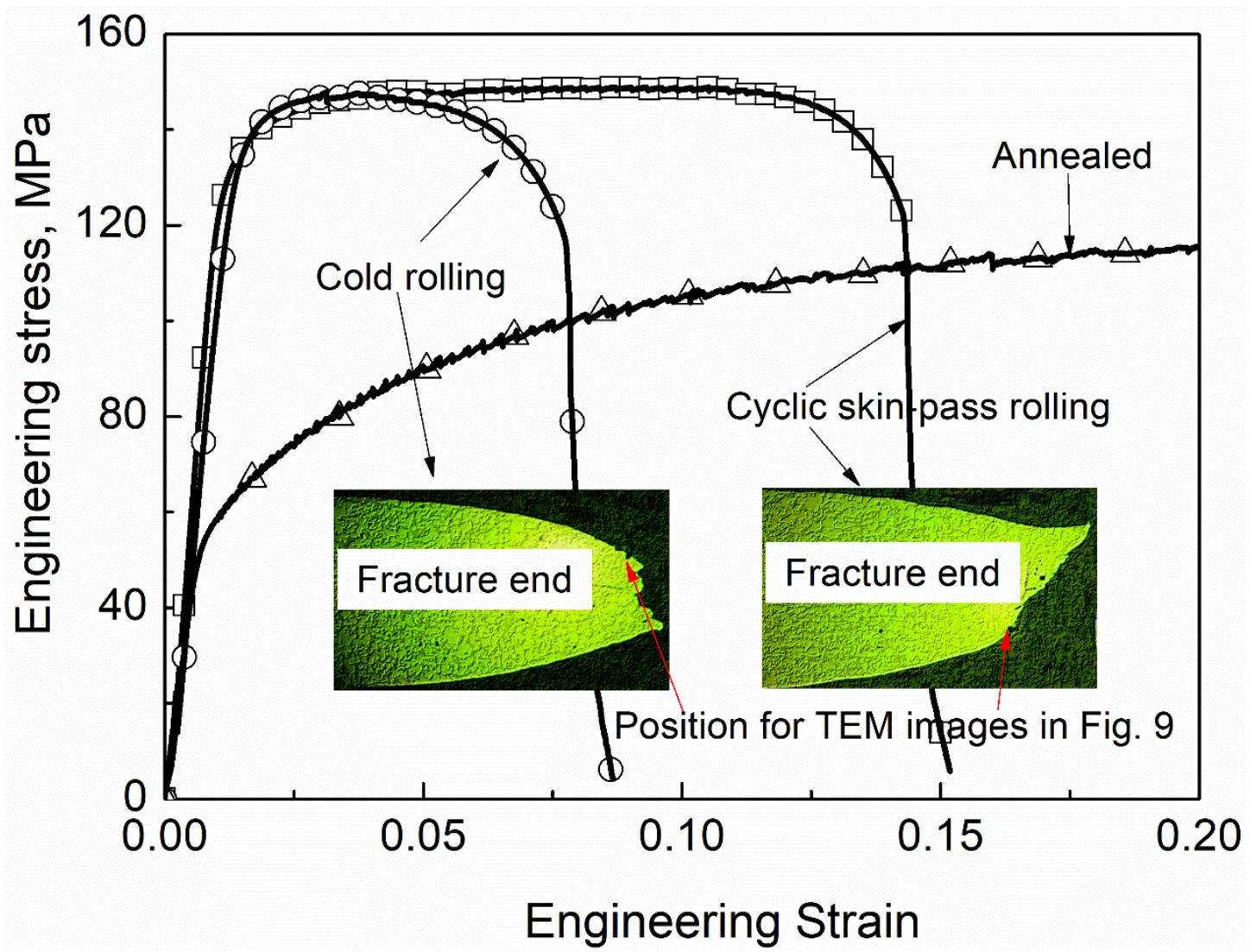

Figure 4. Engineering stress-strain curves of CSPR-processed, CR-processed and annealed sheets. 

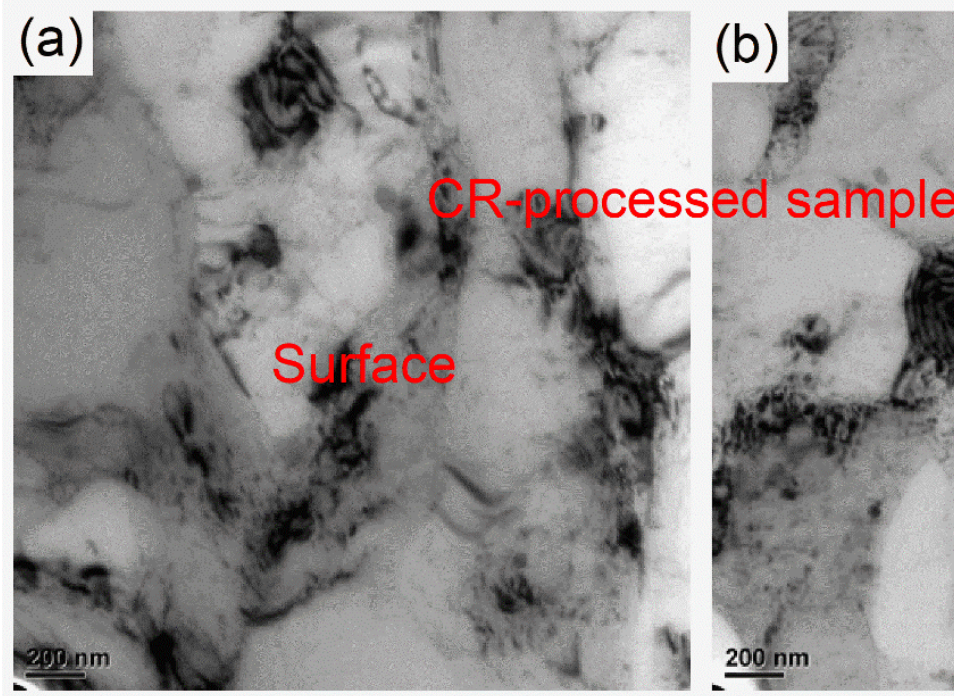

(c)

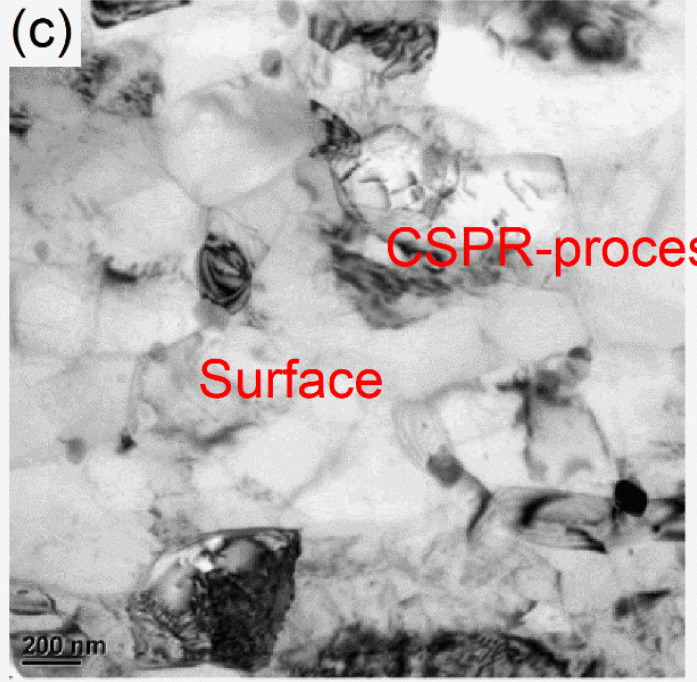

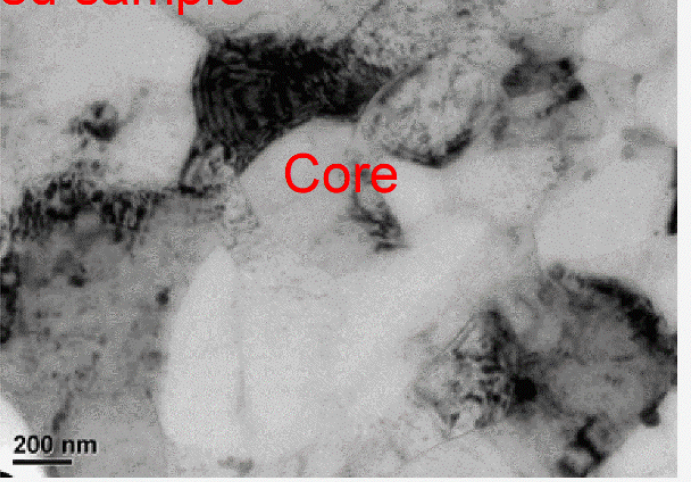

(d)

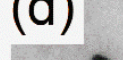

ssed sample

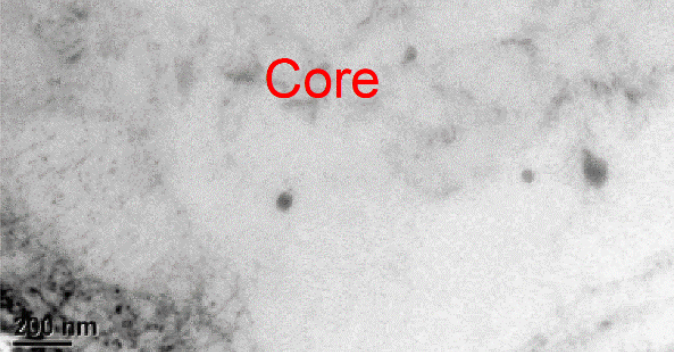

Figure 5. TEM images of rolled samples: (a1) surface and (a2) core of CR-processed samples respectively; (b1) surface and (b2) core of CSPR-processed samples respectively. 

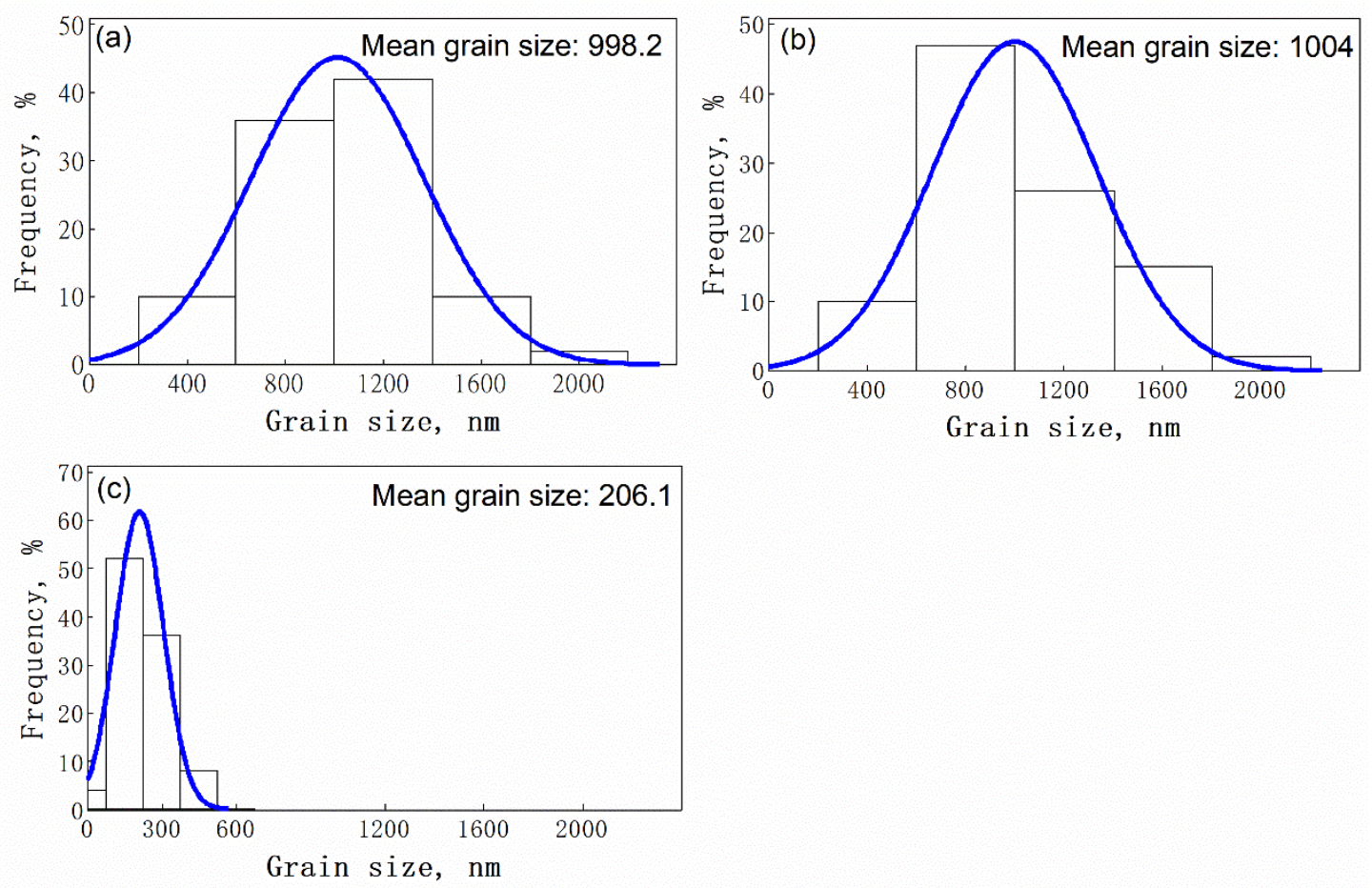

Figure 6. Grain size distribution. (a) near surface of aluminium sheet by CR, (b) center of aluminium sheet by CR, and (c) near surface of aluminium sheet by CSPR. 

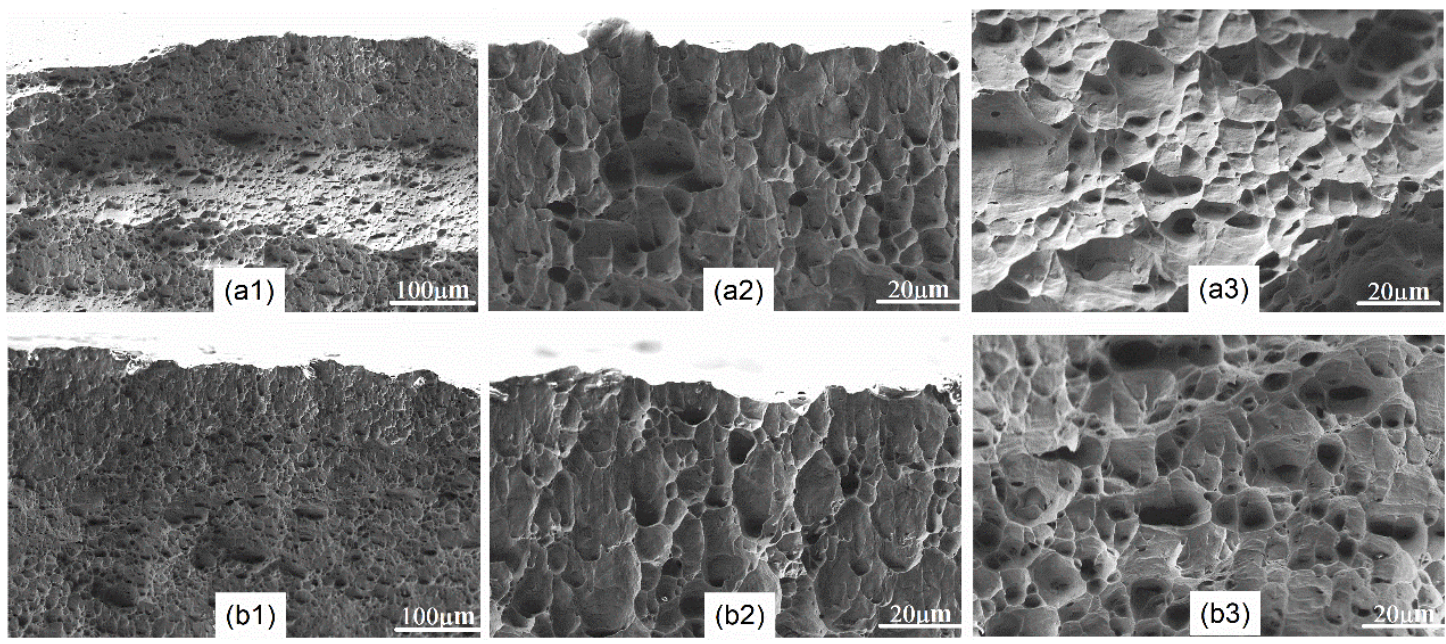

Figure 7. Fracture surface of samples. (a1)-(a3) for cold rolling, (a2) for sample surface and (a3) for sample core; (b1)-(b3) for skin-pass rolling, (b2) for sample surface and (b3) for sample core. 


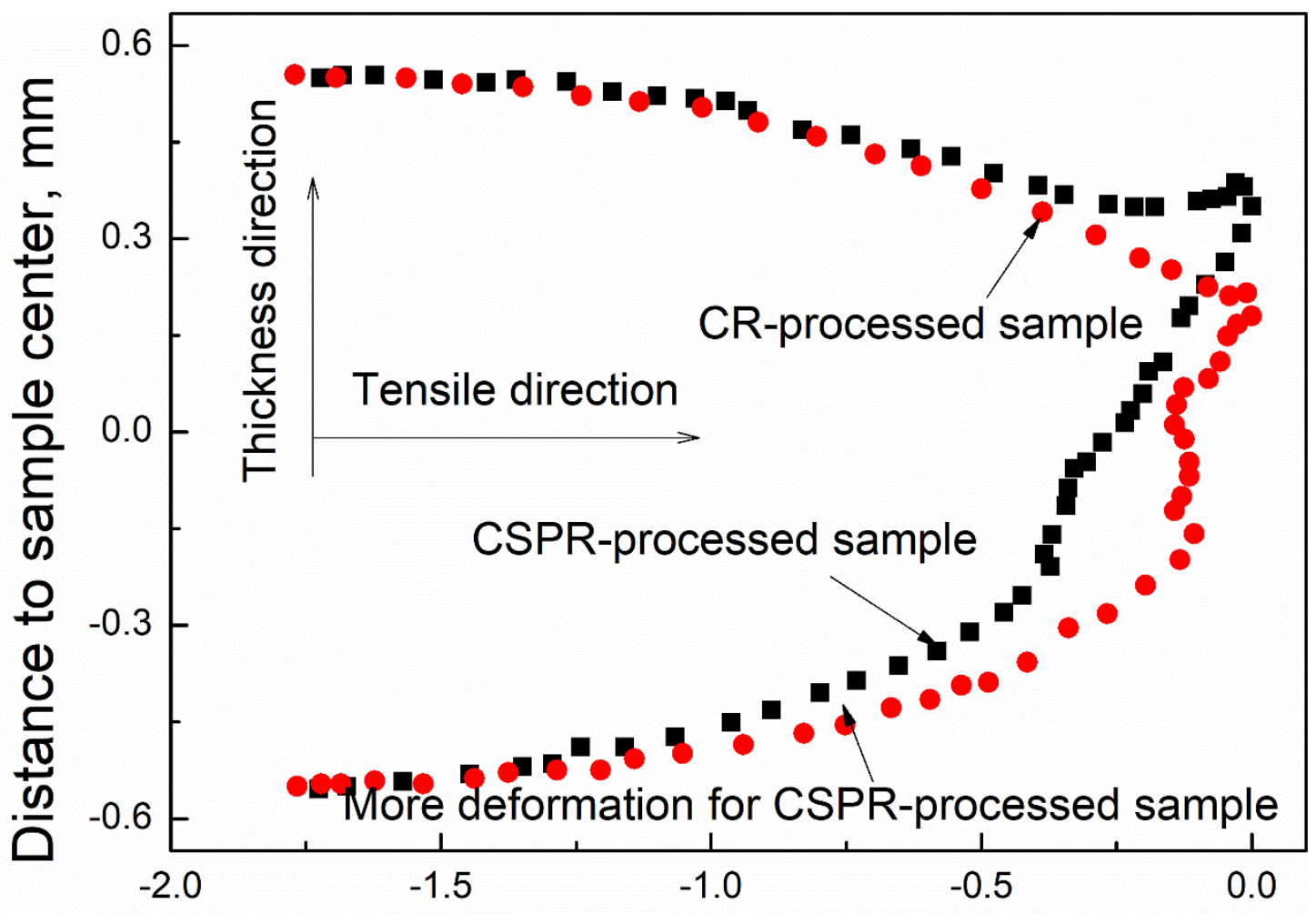

Distance to the end of fractured sample, $\mathrm{mm}$

Figure 8. Geometrical shape of fractured samples after tensile test. 


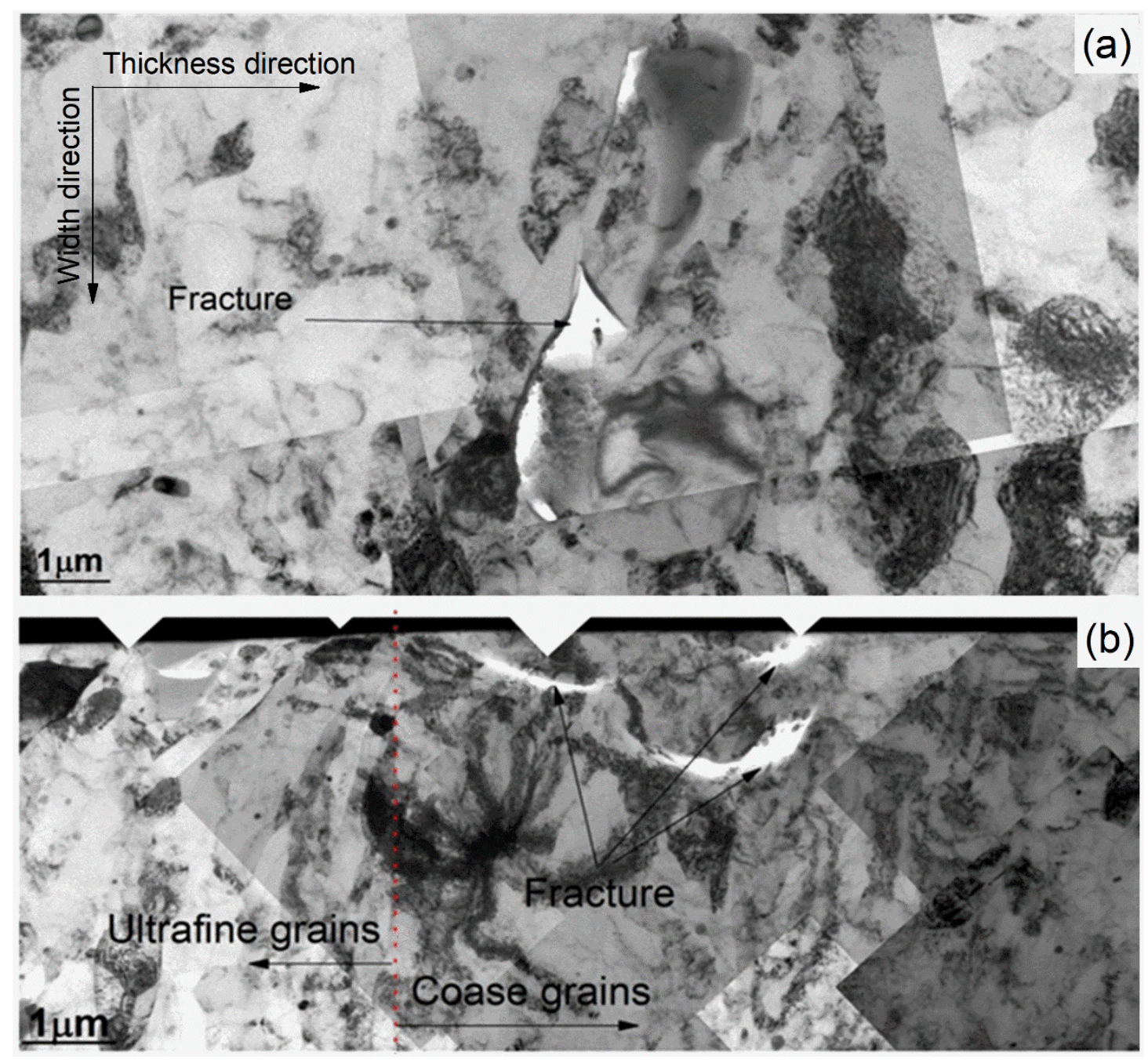

Figure 9. TEM images of fracture end of sheets by (a) CR and (b) CSPR respectively. 


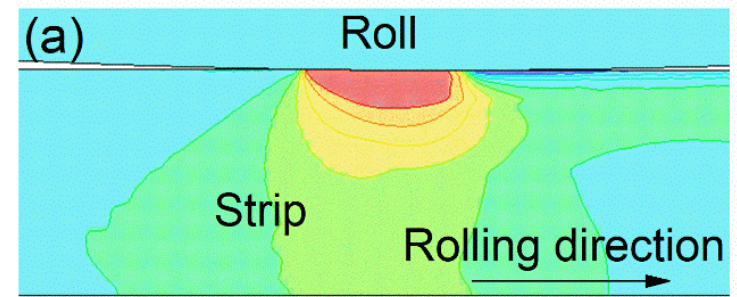

(c)

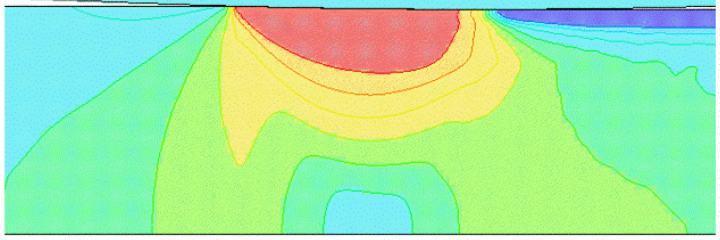

(b)

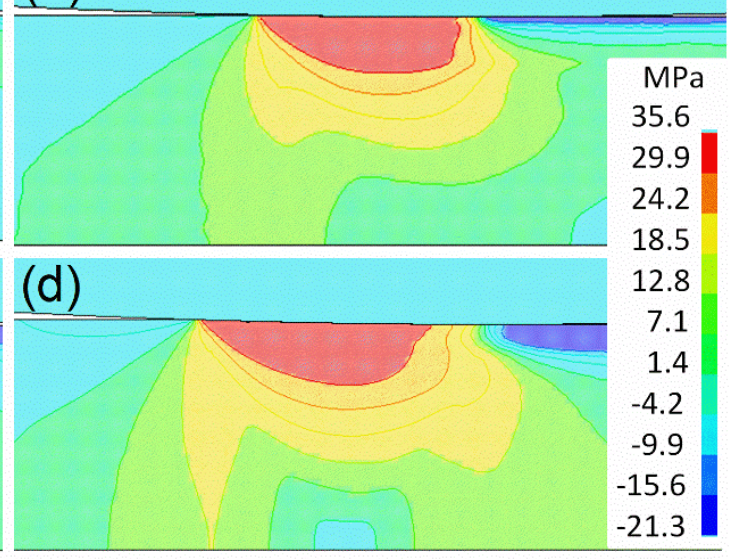

Figure 10. Pressure distribution in sheet during SPR with rolling reduction ratio (a)

$0.5 \%$, (b) $1.0 \%$, (c) $1.5 \%$ and (d) $2.0 \%$. 


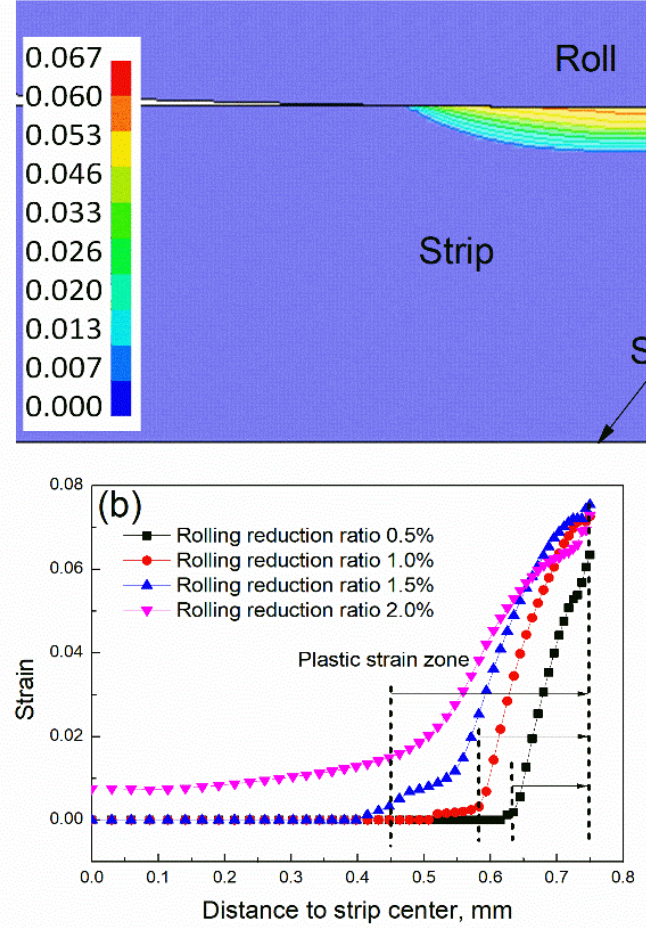

Strip center

Figure 11. (a) strain distribution in sheet during skin pass rolling with rolling

reduction ratio $0.5 \%$; (b) strain distribution corresponding to different reduction ratios. 


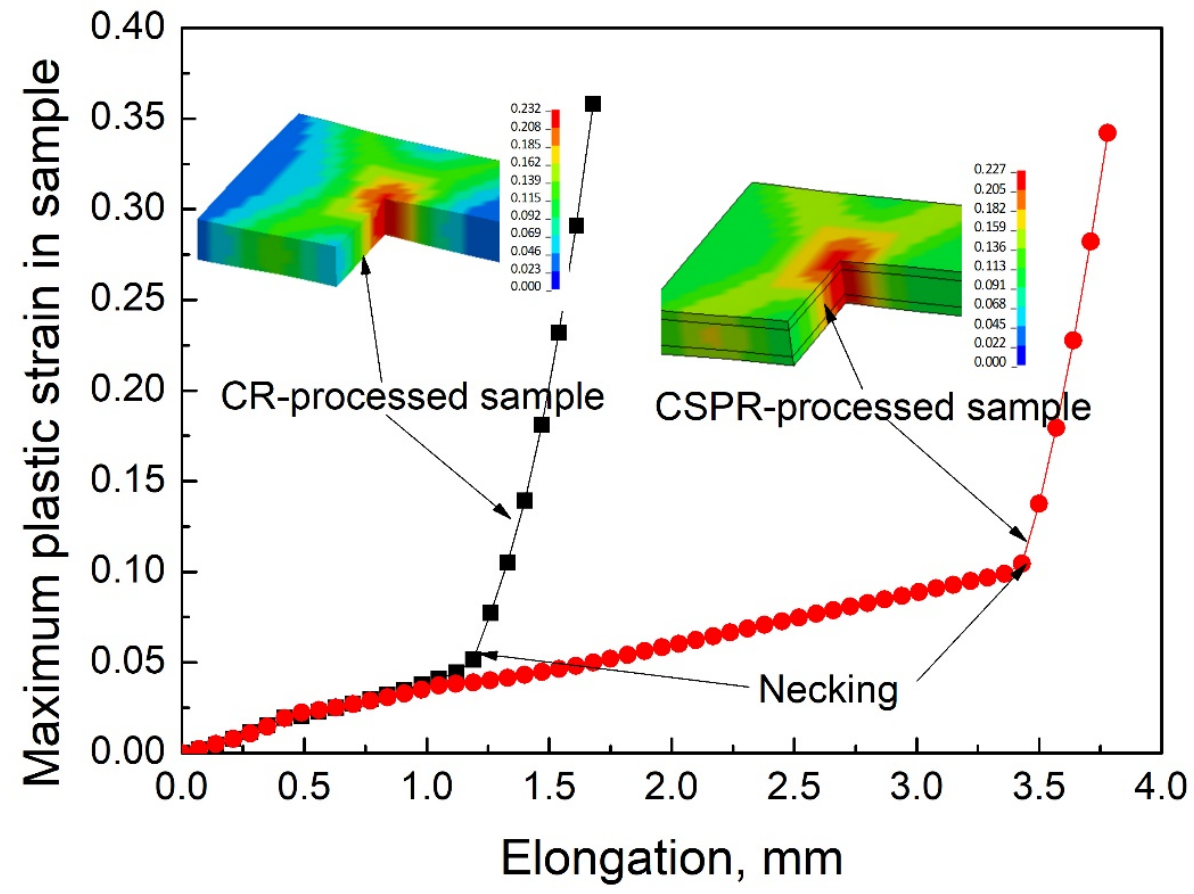

Figure 12. Maximum plastic strain in CR-processed and CSPR-processed samples vs elongation during tensile test. 


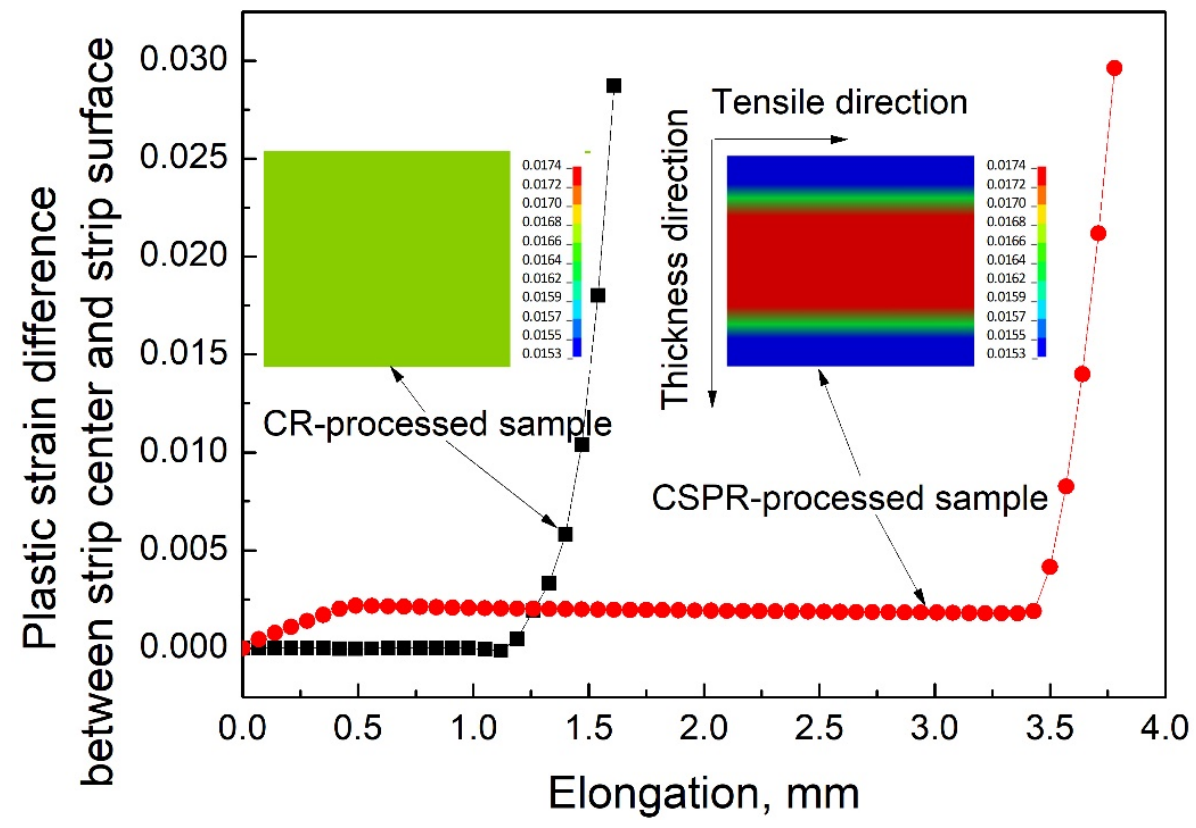

Figure 13. Plastic strain difference between sample center and surface in CR-processed and CSPR-processed samples vs elongation during tensile test. 
(a)

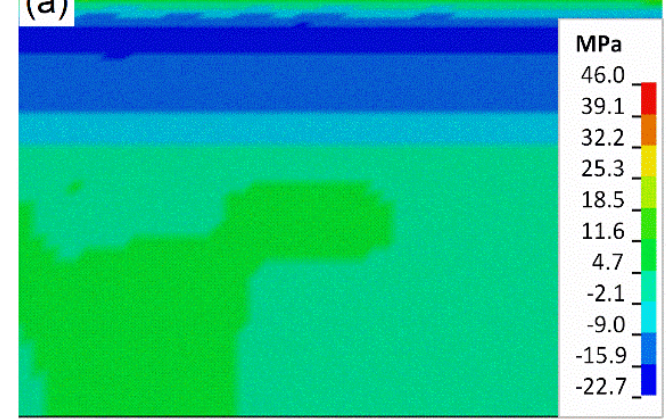

(c)

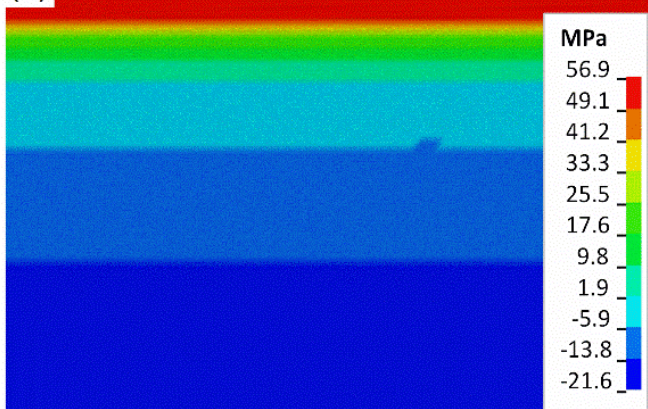

(b)
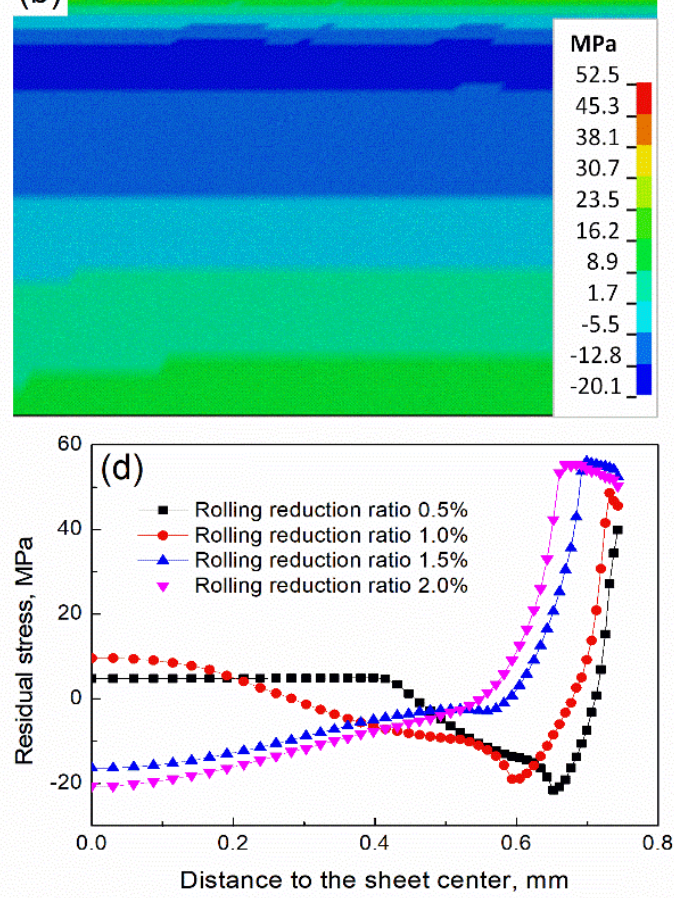

Figure 14. Residual stress in sheet after a rolling pass for rolling reduction ratio (a)

$0.5 \%$, (b) $1.0 \%$, (c) $2.0 \%$. (d) residual stress cross the sheet thickness. 

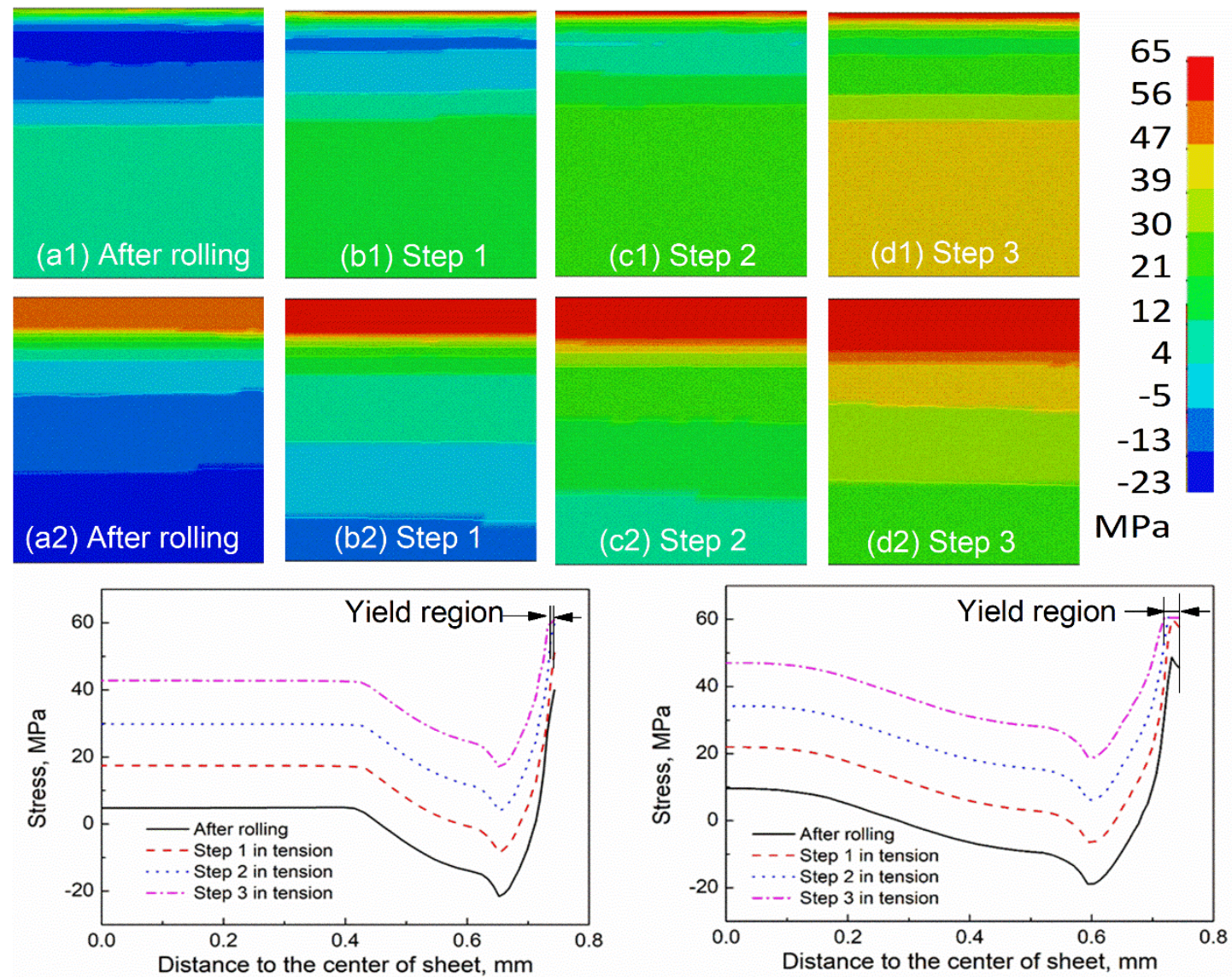

(e)

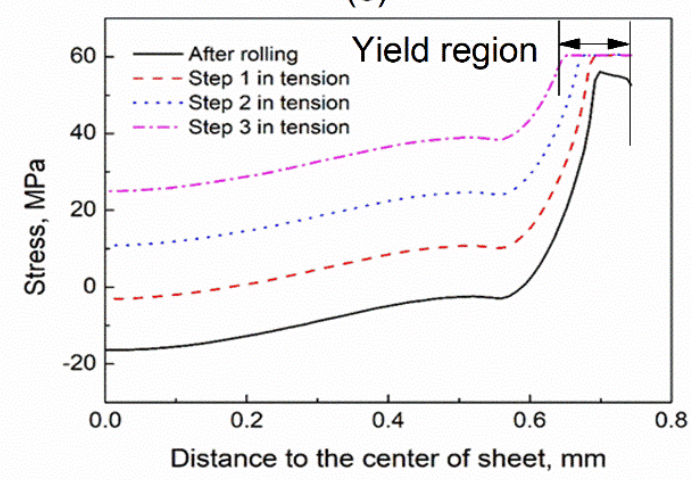

(g)

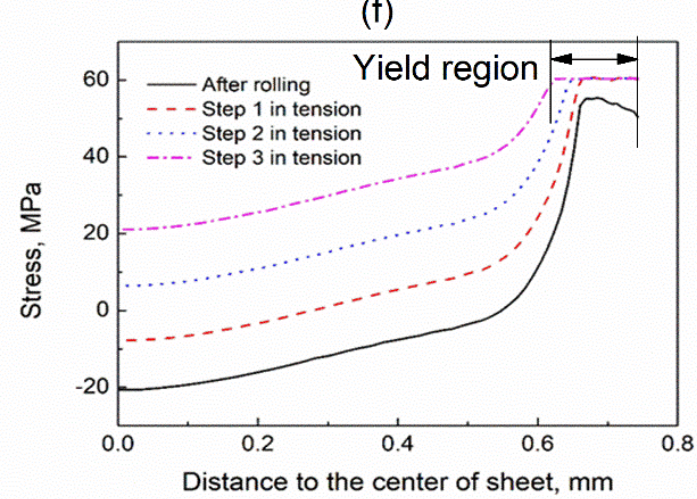

(h)

Figure 15. Evolution of stress during tensile processing considered the residual stress after rolling, (a1)-(d1) for reduction ratio $0.5 \%$ and (a2)-(d2) for reduction ratio $2.0 \%$. Stress value cross the sheet thickness during tensile processing considered the residual stress for rolling reduction ratio (e) $0.5 \%$, (f) $1.0 \%$, (g) $1.5 \%$ and (h) $2.0 \%$. 